\title{
Differences in carbon source utilisation distinguish Campylobacter jejuni from Campylobacter coli
}

\author{
Sariqa Wagley ${ }^{1 *}$, Jane Newcombe ${ }^{4}$, Emma Laing $^{4}$, Emmanuel Yusuf ${ }^{4}$, Christine M Sambles $^{1}$, David J Studholme ${ }^{1}$, \\ Roberto M La Ragione ${ }^{2,3}$, Richard W Titball' ${ }^{1}$ and Olivia L Champion ${ }^{1}$
}

\begin{abstract}
Background: Campylobacter jejuni and C. coli are human intestinal pathogens that are the most frequent causes of bacterial foodborne gastroenteritis in humans in the UK. In this study, we aimed to characterise the metabolic diversity of both C. jejuni and C. coli using a diverse panel of clinical strains isolated from the UK, Pakistan and Thailand, thereby representing both the developed and developing world. Our aim was to apply multi genome analysis and Biolog phenotyping to determine differences in carbon source utilisation by C. jejuni and C. coli strains.

Results: We have identified a core set of carbon sources (utilised by all strains tested) and a set that are differentially utilised for a diverse panel of thirteen C. jejuni and two C. coli strains. This study used multi genome analysis to show that propionic acid is utilised only by C. coli strains tested. A broader PCR screen of 16 C. coli strains and 42 C. jejuni confirmed the absence of the genes needed for propanoate metabolism.

Conclusions: From our analysis we have identified a phenotypic method and two genotypic methods based on propionic utilisation that might be applicable for distinguishing between C. jejuni and C. coli.
\end{abstract}

Keywords: C. jejuni, C. coli, Propanoate metabolism

\section{Background}

Campylobacter species are a major cause of food-borne disease in the developed and the developing world. Over $80 \%$ of human cases are caused by Campylobacter jejuni and around $10 \%$ by Campylobacter coli, with the remaining human cases caused by other Campylobacter species. The species C. jejuni and C. coli are considered to be commensals of birds, domestic pets and livestock, but they have also been isolated from other sources including water, molluscs, bank voles and milk $[1,2]$. Disease in humans is most frequently associated with the consumption of contaminated poultry $(C$. jejuni) or porcine products (C. coli) [3].

Some past studies have begun to define the metabolic requirements of $C$. jejuni, [4-7], yet there is still a paucity of information regarding the metabolic flexibility of

\footnotetext{
* Correspondence: S.Wagley@exeter.ac.uk

'Biosciences, College of Life and Environmental Sciences, University of Exeter, Geoffrey Pope Building, Stocker Road, Exeter EX4 4QD, UK

Full list of author information is available at the end of the article
}

this bacterium, which is able to survive in such a wide range of environmental niches. It is well recognised that amino acids are important carbon and energy sources for C. jejuni, both in vitro and in vivo [8-11]. Serine, aspartic acid, glutamic acid and proline are the most common amino acids found in chicken faeces $[4,12]$ and are therefore possible nutrient sources for $C$. jejuni in the chicken gut. C. jejuni preferentially metabolises amino acids in a specific order: serine, aspartatic acid, asparagine and then glutamic acid. Proline can also be metabolised, but only after other nutrients have been exhausted [13].

Campylobacter species were considered to be asaccharolytic and thus unable to metabolise glucose or other carbohydrates due to the absence of the glycolytic enzyme phosphofructokinase of the Embden-Meyerhof-Parnas (EMP) pathway and incomplete pentose phosphate (PPP) and Entner Doudoroff (ED) pathways $[10,14]$. However, it was recently shown that a novel L-fucose pathway including L-fucose permease is present within a genomic island 
in certain strains of $C$. jejuni $[4,15]$. These studies demonstrated that some $C$. jejuni strains can metabolise the sugar L-fucose. Furthermore, Stahl and co-workers found that fucose transport in $C$. jejuni in vivo provided these strains with a competitive advantage during colonisation of the piglet infection model [4]. However, there have been no subsequent reports of $C$. jejuni carbohydrate metabolism.

Citric acid cycle intermediates such as pyruvate, fumarate, oxaloacetate and 2-oxoglutarate, succinate, fumarate and malate have been reported as energy sources for C. jejuni $[6,10,16]$. In addition, $C$. jejuni has been reported to metabolise short-chain fatty acids (SCFA) $[9,13]$. Acetate, propionate and butyrate are the most significant anion or salt derivatives of SCFAs that are produced as metabolic by-products from the gut microbiota [17].

The capacity for Campylobacter species to survive and thrive in a wide range of environmental niches is underpinned by the ability of the bacteria to utilise the different metabolites that are available in the various hosts and environments. In contrast to the $C$. jejuni studies described above, very little is known about the metabolic requirements of $C$. coli. In this study, we aimed to characterise the metabolic profile of both $C$. jejuni and C. coli in order to see differences in their carbon utilisation capabilities. We used a diverse panel of clinical strains isolated from UK, Pakistan and Thailand, representing both the developed and developing world (Table 1). From our analysis we have identified a phenotypic method and two genotypic methods for distinguishing between $C$. jejuni and $C$. coli.

\section{Results}

Carbon utilisation profiles of $C$. jejuni and $C$. coli strains reveal core and variable metabolites

We initially selected 13 human C. jejuni isolates and two human $C$. coli isolates to assess their metabolic profiles. Using BIOLOG PM1 and PM2 carbon utilisation plates, we identified the core (utilised by $100 \%$ of strains tested) and differential carbon sources (utilised by $<90 \%$ of strains tested) utilised by a diverse panel of 13 C. jejuni and two C. coli strains (Table 2). The Omnilog software (Hayward, California USA) generates a reading every 15 mins corresponding to the conversion of the redox dye used in the assay and hence respiration levels. The entire experiment was repeated at least in triplicate for each strain. The mean values of the experimental replicates for each strain for each carbon substrate were compared by one way ANOVA and Tukey multiple comparison of means using a 95\% family-wise confidence level. Statistical significance was assigned at the $\mathrm{P}<0.05$ level (see Additional file 1). Core carbon sources included the amino acids L-aspartic acid, L-asparagine, L-proline and L-serine. Citric acid cycle intermediate succinic acid and its derivative bromo-succinic acid were used by all strains. D,L malic acid, fumaric acid and methyl pyruvic acid were also metabolised by all of the strains. When D-malic acid was used as a sole carbon source it was only utilised by $C$. jejuni strains and not by the two C. coli strains tested. Lactic acid, butyric acid and D-lactic acid methyl ester were utilised by all strains while formic acid was utilised by 14 of the 15 strains tested.

Differential carbon sources (utilised by $<90 \%$ of tested strains) included the carbohydrate L-fucose, supporting recent reports that some strains of $C$. jejuni are able to utilise carbohydrates [4]. We found differential metabolism of the amino acids L-glutamine, glycyl-L-glutamic acid and glycine-L-proline and citric acid cycle intermediates alpha-keto-glutaric acid, citric acid, glycolic acid, glyoxylic acid, tricarballyic acid. The metabolic profiles of all the strains can be found in Additional file 1 . Finally, the SCFA propionic acid, was metabolised by both $C$. coli strains tested (K3 and K7) but was not metabolised by any of the C. jejuni strains (Table 2).

\section{Whole-genome sequencing reveals genes encoding propanoate metabolism enzymes in $C$. coli that are absent from $C$. jejuni}

To identify the genetic basis for propionic acid metabolism in C. coli, we sequenced the genomes of two C. coli strains (isolated from individuals suffering from diarrhoeal disease in Pakistan (Table 1). Data from these wholegenome shotgun projects have been deposited at DDBJ/ EMBL/GenBank under the accessions AYKO00000000 and AYKN00000000. The versions described in this paper are version AYKO01000000 and AYKN00000000. We used the RAST webserver [23] to examine the presence or absence of enzymes in the propanoate metabolism pathway (KEGG: ko00640) for C. jejuni strains NCTC 11168 [22], 81116 [19] and 81176 [20] and C. coli strains K3 and $\mathrm{K} 7$ and found that genes encoding propionate-CoA ligase (PrpE/EC 6.2.1.17) and 2-methyl-citrate synthase (PrpC/ EC 2.3.3.5) were present in the genomes of both $C$. coli strains but were absent from the $C$. jejuni genome sequences (see Figure 1).

To assess whether the presence or absence of propionate-CoA ligase and 2-methyl-citrate synthase genes could be used to distinguish $C$. coli from $C$. jejuni, we next searched the NCBI non-redundant nucleotide sequence database [24] for similar sequences using Blastn [25]. We also performed these searches against the 66 publicly available complete and draft $C$. coli genome sequences in RefSeq [26]. Homologues of propionate-CoA ligase and 2-methyl-citrate synthase genes were identified in all (66/66) of the $C$. coli genomes interrogated and with a minimum of $99 \%$ identity across the entire gene sequences. In contrast, when the 84 publicly available C. jejuni complete and draft genomes were interrogated 
Table 1 List of $C$. jejuni and $C$. coli strains used in this study

\begin{tabular}{|c|c|c|c|c|c|c|c|}
\hline Species & Strain name & Source & Country of origin & 2-methylcitrate synthase & Propionate-CoA ligase & gltA & Strain source \\
\hline$\overline{\text { C. coli }}$ & $1 / 12$ & Human & UK & + & + & + & This study \\
\hline C. coli & $90-3$ & - & - & NT & NT & NT & AIMJ01000007.1 \\
\hline C. coli & 2548 & - & - & NT & NT & NT & AIML01000019.1 \\
\hline C. coli & JV 20 & - & USA & NT & NT & NT & AEER01000027.1 \\
\hline C. coli & $K 3^{*}$ & Human & Pakistan & + & + & + & This study \\
\hline C. coli & $K 7^{*}$ & Human & Pakistan & + & + & + & This study \\
\hline C. coli & PS304* & Pig & UK & + & + & + & This study \\
\hline C. coli & $\mathrm{R} 03 / 167^{*}$ & Cattle & UK & + & + & + & This study \\
\hline C. coli & R03/389* & Sheep & UK & + & + & + & This study \\
\hline C. coli & R03/393* & Cattle & UK & + & + & + & This study \\
\hline C. coli & $\mathrm{R} 04 / 28^{*}$ & Sheep & UK & + & + & + & This study \\
\hline C. coli & RM 2228 & Chicken & USA & NT & NT & NT & [18] \\
\hline C. coli & S03/35* & Pig & UK & + & + & + & This study \\
\hline C. coli & S03/468* & Cattle & UK & + & + & + & This study \\
\hline C. coli & S03/475* & Pig & UK & + & + & + & This study \\
\hline C. coli & S03/704* & Pig & UK & + & + & + & This study \\
\hline C. coli & S03/749* & Sheep & UK & + & + & + & This study \\
\hline C. coli & S03/954* & Sheep & UK & + & + & + & This study \\
\hline C. coli & S39-2-99-3* & Sheep & UK & + & + & + & This study \\
\hline C. coli & Z163 & - & - & NT & NT & NT & AIMK01000002.1 \\
\hline C. coli & MB17 & Poultry & UK & + & + & + & This study \\
\hline C. jejuni & 74 & Goose & - & - & - & + & This study \\
\hline C. jejuni & $95^{*}$ & Goose & - & - & - & + & This study \\
\hline C. jejuni & $91 \mathrm{~B} 1$ & Chicken & - & - & - & + & This study \\
\hline C. jejuni & $99 / 201$ & Cow & UK & - & - & + & This study \\
\hline C. jejuni & $99 / 212$ & Human & UK & - & - & + & This study \\
\hline C. jejuni & $222^{*}$ & Goose & - & - & - & + & This study \\
\hline C. jejuni & 11818 & Human & UK & - & - & + & This study \\
\hline C. jejuni & $11919^{*}$ & Human & UK & - & - & + & This study \\
\hline C. jejuni & $11974^{*}$ & Human & UK & - & - & + & This study \\
\hline C. jejuni & $12241^{*}$ & Human & UK & - & - & + & This study \\
\hline C. jejuni & $13305^{*}$ & Human & UK & - & - & + & This study \\
\hline C. jejuni & 18629 & Unknown & - & - & - & + & This study \\
\hline C. jejuni & $18836^{*}$ & Unknown & - & - & - & + & This study \\
\hline C. jejuni & $30280^{*}$ & Human & UK & - & - & + & This study \\
\hline C. jejuni & $30328^{*}$ & Unknown & - & - & - & + & This study \\
\hline C. jejuni & 31407 & Unknown & - & - & - & + & This study \\
\hline C. jejuni & 31481 & Unknown & - & - & - & + & This study \\
\hline C. jejuni & 31484 & Human & UK & - & - & + & This study \\
\hline C. jejuni & 31485 & Human & UK & - & - & + & This study \\
\hline C. jejuni & 32787 & Human & UK & - & - & + & This study \\
\hline C. jejuni & $32799^{*}$ & Human & UK & - & - & + & This study \\
\hline C. jejuni & $33084^{*}$ & Human & UK & - & - & + & This study \\
\hline C. jejuni & 33106 & Human & UK & - & - & + & This study \\
\hline
\end{tabular}


Table 1 List of C. jejuni and C. coli strains used in this study (Continued)

\begin{tabular}{|c|c|c|c|c|c|c|c|}
\hline C. jejuni & 34007 & Human & UK & - & - & + & This study \\
\hline C. jejuni & 40483 & Unknown & - & - & - & + & This study \\
\hline C. jejuni & 41730 & Unknown & - & - & - & + & This study \\
\hline C. jejuni & $44119^{*}$ & Human & UK & - & - & + & This study \\
\hline C. jejuni & $47693^{*}$ & Human & UK & - & - & + & This study \\
\hline C. jejuni & $81116^{*}$ & Human & - & NT & NT & NT & [19] \\
\hline C. jejuni & $81176^{*}$ & Human & USA & NT & NT & NT & [20] \\
\hline C. jejuni & 81205 & Unknown & - & - & - & + & This study \\
\hline C. jejuni & A6.T2.15* & Poultry & UK & - & - & + & This study \\
\hline C. jejuni & A8.35.15A* & Poultry & UK & - & - & + & This study \\
\hline C. jejuni & ATCC 43431 & Human & - & - & - & + & [21] \\
\hline C. jejuni & $\mathrm{BB} 1267^{*}$ & Human & UK & - & - & + & This study \\
\hline C. jejuni & $\mathrm{C} 1 / \mathrm{C} / 2^{*}$ & Poultry & UK & - & - & + & This study \\
\hline C. jejuni & C5/T2/8 & Poultry & UK & - & - & + & This study \\
\hline C. jejuni & $\mathrm{Cj} 1^{*}$ & Human & Thailand & - & - & + & This study \\
\hline C. jejuni & $\mathrm{Cj} 2^{*}$ & Human & Thailand & NT & NT & NT & This study \\
\hline C. jejuni & $\mathrm{Cj} 3 *+$ & Human & Thailand & NT & NT & NT & This study \\
\hline C. jejuni & Cj5* & Human & Thailand & - & - & + & This study \\
\hline C. jejuni & $\mathrm{D} 2 / \mathrm{T} / 8$ & Poultry & UK & - & - & + & This study \\
\hline C. jejuni & D2/T/95 & Poultry & UK & - & - & + & This study \\
\hline C. jejuni & $\mathrm{K} 1^{*}$ & Human & Pakistan & NT & NT & NT & This study \\
\hline C. jejuni & $\mathrm{K} 2^{*}$ & Human & Pakistan & NT & NT & NT & This study \\
\hline C. jejuni & $K 4^{*}$ & Human & Pakistan & NT & NT & NT & This study \\
\hline C. jejuni & $\mathrm{K} 5^{*}$ & Human & Pakistan & NT & NT & NT & This study \\
\hline C. jejuni & $K 6^{*}$ & Human & Pakistan & - & - & + & This study \\
\hline C. jejuni & MB16 & Poultry & UK & - & - & + & This study \\
\hline C. jejuni & MB18 & Poultry & UK & - & - & + & This study \\
\hline C. jejuni & NCTC11168* & Human & - & - & - & + & [22] \\
\hline
\end{tabular}

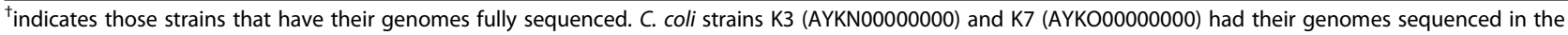
scope of this study.

*indicates those strains used in the Biolog studies. NT indicates strains not tested.

we did not identify genes that could encode propionateCoA ligase or 2-methyl-citrate synthase.

\section{A PCR assay for the propionate-CoA ligase or 2 methyl-citrate-synthase genes can be used to distinguish C. coli from C. jejuni}

An amino acid sequence alignment of propionate-CoA ligase and 2-methyl-citrate-synthase from $C$. coli revealed that these proteins are highly conserved across six randomly selected $C$. coli isolates (see Additional file 2). PCR amplification of the propionate-CoA ligase or 2-methyl-citrate synthase genes using $C$. coli or $C$. jejuni template DNA generated amplicons of the expected size from all 15 strains of $C$. coli tested. In contrast, amplicons were not generated using template DNA from 42 of 43 strains of $C$. jejuni tested. The single isolate (MB17 previously characterised as $C$. jejuni) that generated PCR amplicons was subsequently shown to give a negative reaction in the hippurate hydrolysis assay, indicating that this strain had been incorrectly assigned as $C$. jejuni. Therefore, $100 \%$ (42/42) of the C. jejuni strains failed to yield amplicons. Positive-control PCR assays for the housekeeping gene gltA (encoding citrate synthase) generated amplicons from all of the $C$. jejuni and $C$. coli isolates tested.

Propionic acid as a sole carbon source allows differential identification of $C$. coli and $C$. jejuni

To determine whether $C$. coli and $C$. jejuni differed in their ability to utilise propionic acid as a sole carbon source in culture medium, we tested a panel of 16 environmental and clinical C. coli strains and 17 C. jejuni strains in BIOLOG phenotypic microarray plates containing propionic acid as the sole carbon source. No or weak 
Table 2 Core and differential carbon sources utilised by strains used in this study

\begin{tabular}{|c|c|c|c|c|c|c|c|c|c|c|c|c|c|c|c|c|}
\hline & \multirow[t]{2}{*}{ Carbon source } & \multicolumn{13}{|c|}{ C. jejuni } & \multicolumn{2}{|c|}{ C. coli } \\
\hline & & $\mathrm{K} 1$ & $\mathrm{~K} 2$ & K4 & K5 & K6 & 81176 & 81116 & 11168 & 32799 & 33084 & Cj1 & $\mathrm{Cj} 2$ & $\mathrm{Cj5}$ & K3 & K7 \\
\hline \multirow[t]{6}{*}{ Amino Acids } & L-Proline & + & + & + & + & + & + & + & + & + & + & + & + & + & + & + \\
\hline & L-Asparagine & + & + & + & + & + & + & + & + & + & + & + & + & + & + & + \\
\hline & L-Serine & + & + & + & + & + & + & + & + & + & + & + & + & + & + & + \\
\hline & L-Aspartic Acid & + & + & + & + & + & + & + & + & + & + & + & + & + & + & + \\
\hline & L-Glutamic Acid & + & + & + & + & + & + & - & + & + & - & + & + & - & + & + \\
\hline & L-Glutamine & + & + & + & + & + & + & + & + & + & - & + & + & - & + & + \\
\hline \multirow[t]{8}{*}{ Citric Acid Intermediates } & Methyl Pyruvate & + & + & + & + & + & + & + & + & + & + & + & + & + & + & + \\
\hline & L-Malic Acid & + & + & + & + & + & + & + & + & + & + & + & + & + & + & + \\
\hline & Succinic Acid & + & + & + & + & + & + & + & + & + & + & + & + & + & + & + \\
\hline & D,L-Malic Acid & + & + & + & + & + & + & + & + & + & + & + & + & + & + & + \\
\hline & Bromo Succinic Acid & + & + & + & + & + & + & + & + & + & + & + & + & + & + & + \\
\hline & Fumaric Acid & + & + & + & + & + & + & + & + & + & + & + & + & + & + & + \\
\hline & Mono Methyl Succinate & + & + & + & + & + & + & + & - & + & + & + & - & + & + & + \\
\hline & D-Malic Acid & + & + & + & + & + & + & + & + & + & + & + & + & + & - & - \\
\hline \multirow[t]{5}{*}{ Carboxylic Acids } & L-Lactic Acid & + & + & + & + & + & + & + & + & + & + & + & + & + & + & + \\
\hline & D-Lactic Acid Methyl Ester & + & + & + & + & + & + & + & + & + & + & + & + & + & + & + \\
\hline & a-Hydroxy Butyric Acid & + & + & + & + & + & + & + & + & + & + & + & + & + & + & + \\
\hline & Formic Acid & + & + & + & + & + & + & + & + & - & + & + & + & + & + & + \\
\hline & Propionic Acid & - & - & - & - & - & - & - & - & - & - & - & - & - & + & + \\
\hline Carbohydrates & L-Fucose & - & - & - & - & - & - & - & - & + & - & + & - & - & + & + \\
\hline
\end{tabular}

The carbon sources that are core to all the strains have been highlighted in bold.

propionic utilisation was seen in all $C$. jejuni strains tested while strong propionic utilisation was seen for all $C$. coli strains tested. The mean values of the experimental replicates for each strain were compared using a unpaired $T$ test with Welch's correction. Statistical significance was assigned at $\mathrm{P}<0.0001$ level indicating a difference between propionic utilisations by $C$. jejuni and $C$. coli. Figure 2 shows levels of propionic acid utilisation by $C$. jejuni and C. coli strains.

\section{Discussion}

Campylobacter species are fastidious bacteria, exhibiting significant metabolic restrictions compared to other enteropathogenic bacteria. The principal energy sources for C. jejuni are amino acids, citric acid cycle intermediates and short-chain fatty acids [10,27]. Despite these metabolic limitations, Campylobacter species can survive in a wide range of environmental niches suggesting metabolic flexibility. To date, only a few laboratory adapted strains have been used to study the metabolic diversity of Campylobacter species. In this study, we examined the extent of the metabolic diversity of $C$. jejuni and $C$. coli recently isolated from cases of disease.

The catabolism of amino acids by $C$. jejuni not only provides a carbon source but also protects bacteria from osmotic and oxidative stress [28-30]. Moreover, catabolism of particular amino acids can confer tissue-specific advantages for C. jejuni colonisation [11]. Hofreuter and co-workers showed that serine supports growth of C. jejuni in murine intestinal and liver tissue, whereas proline and glutamine support growth in the intestine but not the liver [11]. They also showed that two C. jejuni strains (ATCC 33251 and RM1221) were unable to utilise serine in vitro even though they showed no genetic variation in L-serine dehydratase (SdaA) and the serine transporter $\mathrm{SdaC}$. We have shown in this study that L-serine was utilised by all 13 C. jejuni tested. Amino acids that were differentially utilised by the C. jejuni and C. coli strains included L-glutamine, and glutamic acid. This difference in the metabolic profiles of $C$. jejuni and $C$. coli isolates may indicate adaptation of these strains to different niches and reflect niche specific requirements for amino acids as a nutrient source, such as those reported for Staphylococcus aureus and Francisella novicida [31,32].

Previous studies have concluded that except for a few strains that are able to utilise the carbohydrate L-fucose $[4,10]$, Campylobacter are asaccharolytic. One of the strains shown in previous studies $[4,15]$ to utilise fucose was C. jejuni strain NCTC 11168. In our study, we 


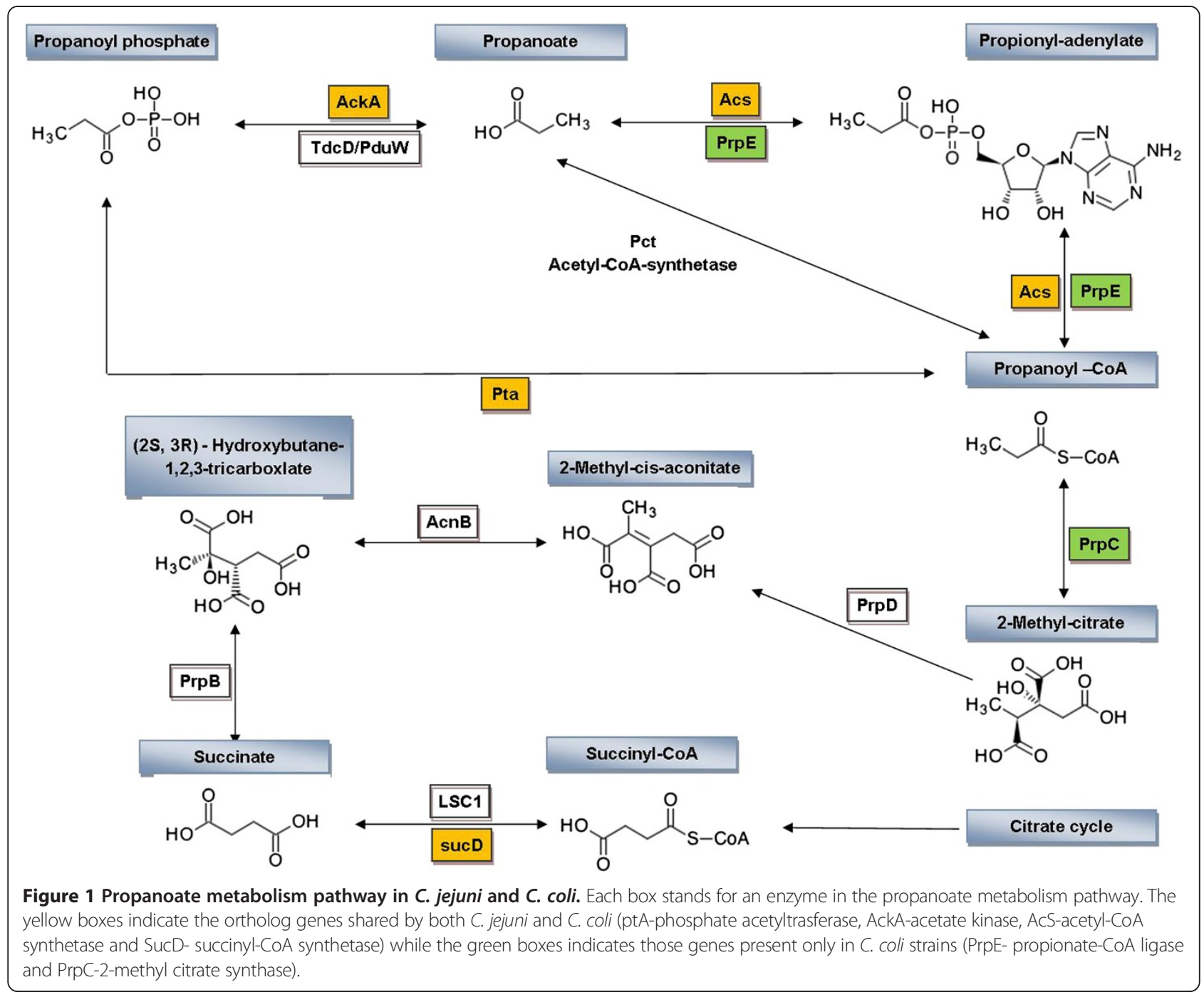

found that strain NCTC 11168 was unable to respire using this carbon source. Other workers have reported differences in strains of NCTC 11168 which may account for this phenotype [33,34]. Furthermore, in a previous study it has been shown that oxidation of some substrates was greater at $42^{\circ} \mathrm{C}$ than $37^{\circ} \mathrm{C}$. This may account for the lack of L-fucose utilisation seen here [35]. The ability of some strains of $C$. jejuni to utilise L-fucose is reportedly associated with the colonisation of pigs, but not poultry [4]. The two $C$. coli strains we tested using the BIOLOG assay were both able to utilise L-fucose. As C. coli is predominately found in pigs, our findings support the suggestion [4] that fucose availability in the pig intestine influences the bacterial fitness of $C$. coli colonisation in this host.

From our study, we found that none of the $C$. jejuni isolates tested were able to metabolise propionic acid while both $C$. coli strains were able to metabolise this carbon source. This appears to be linked to the presence of propanoate-CoA ligase and 2-methyl-synthase genes in $C$. coli and their absence in C. jejuni. Our studies further showed that the absence or presence of these genes is a reliable marker for the identification of $C$. jejuni or C. coli. The power of this test was confirmed by our finding that strain MB17 has been erroneously identified as C. jejuni; this strain tested positive for these two marker genes and our subsequent investigations showed that this was a strain of C. coli.

Propionic acid is the most abundant of four SCFA measured in pig manure [36] and levels of propionate have been reported to be high in the gastrointestinal tract of pigs, one of the natural hosts for C. coli [37]. Competition for nutrients in the gut is fierce and so the ability to use a potentially toxic metabolic waste product as an energy source may confer $C$. coli with a selective advantage when colonising the pig gastrointestinal tract.

Campylobacterioisis is the principal cause of bacterial diarrhoeal disease in humans and C. jejuni and C. coli 


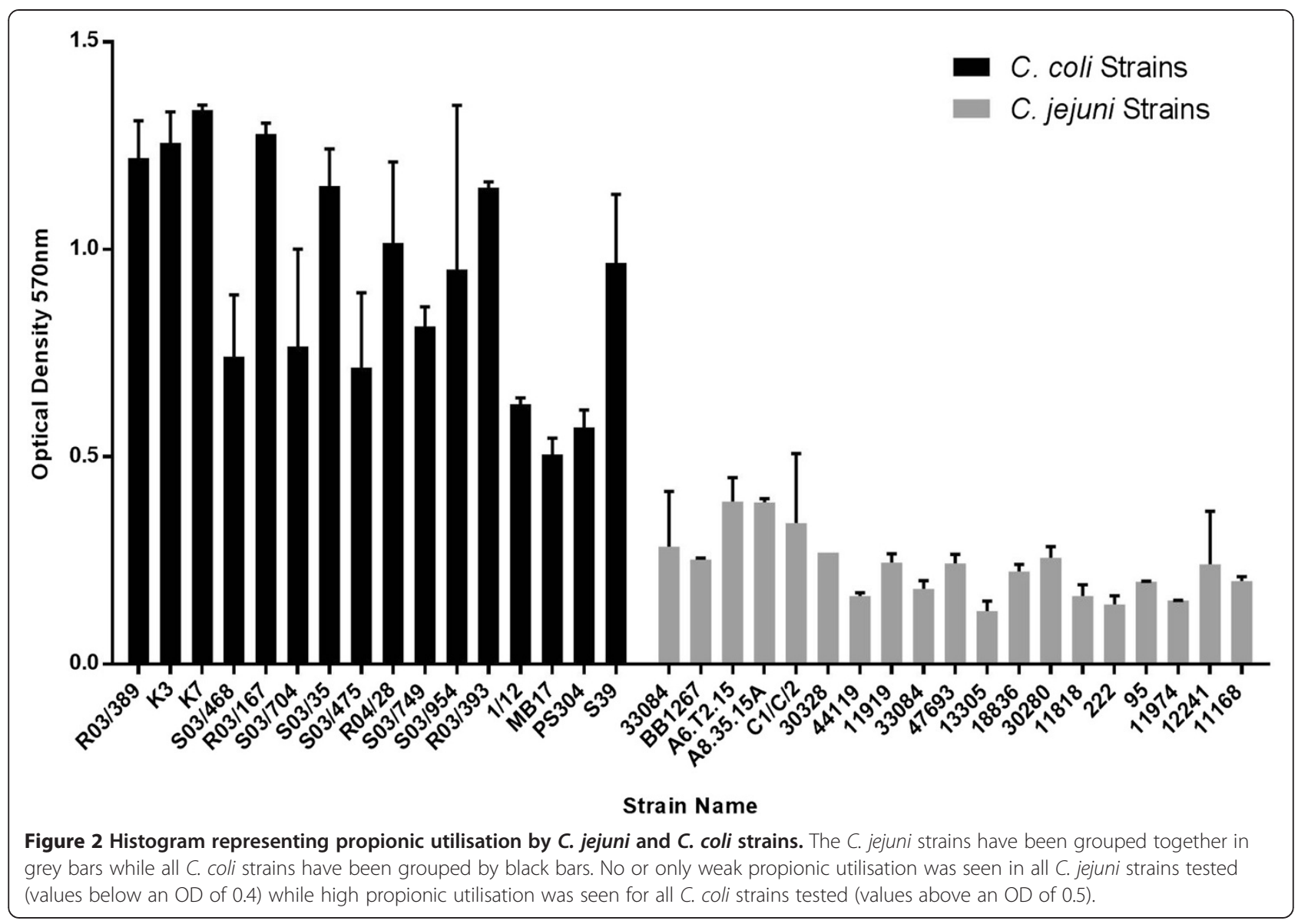

are the most common aetiological agents of human campylobacteriosis. The epidemiology of Campylobacter infections in humans is poorly characterised in low income countries [38]. The true incidence of $C$. coli is difficult to estimate due to the difficulties in distinguishing Campylobacter species. C. jejuni can be distinguished from other Campylobacter species on the basis of the hydrolysis of hippurate for which $C$. jejuni gives only a positive reaction. However, hippurate negative $C$. jejuni strains have occasionally been reported $[39,40]$. Mass spectrometry has also been used to discriminate between Campylobacter species C. coli, C. jejuni, C. helveticus, C. lari, C. sputorum and C. upsaliensis using species identifying biomarkers [41]. However, these methods are time consuming and require complex equipment. Often additional confirmatory tests based upon PCR amplification of a range of genes are needed [42-44]. For example Klena et al., describes a multiplex PCR test to distinguish between $C$. jejuni, $C$. coli, C. coli, C. lari and C. upsaliensis using the lipid A gene $l p x A$ with good species identification.

\section{Conclusion}

Methods that distinguish species of Campylobacter need to be developed in order to understand environmental aspects of Campylobacter epidemiology, the emergence of atypical Campylobacter species, emerging clinical aspects of disease, the association of Campylobacter species with their natural hosts and emerging trends in antibiotic resistance. We have presented a molecular method that allows for accurate discrimination of the two predominant species associated with human disease. In addition, we have identified the basis for a selective media that would permit rapid discrimination of $C$. jejuni and $C$. coli that would be suitable for use in diagnostic and reference laboratories around the world. The importance of identifying C. coli from C. jejuni correctly from both environmental and clinical sources would help broaden our understanding of the distribution, prevalence, geographical spread and transmission of this human pathogen.

\section{Methods}

Strains and culture conditions

All bacterial strains used in this study are shown in Table 1. Campylobacter strains were cultured on Mueller Hinton Agar (Oxoid, UK), Columbia agar plates (CBA) (Oxoid, UK) supplemented with either 5\% (v/v) horse blood or with Skirrow selective supplement (Oxoid, UK) 
in a variable atmosphere incubator (VAIN) (Don Whitley Scientific, UK) under microaerobic conditions $\left(5 \% \mathrm{O}_{2}\right.$, $85 \% \mathrm{~N}_{2}, 10 \% \mathrm{CO}_{2}$ ) at $37^{\circ} \mathrm{C}$ for 24 or $48 \mathrm{~h}$ or alternatively microaerophillic conditions were created using CampyGen Paks (Fisher Ltd).

\section{Genome sequencing, assembly and annotation}

Bacterial cells were harvested and genomic DNA was extracted using Wizard Genomic DNA Purification Kit (Promega A1125). Each gDNA sample was quantified using a Thermo Scientific NanoDrop ${ }^{\mathrm{TM}} 1000$ Spectrophotometer and run on a $1.5 \%$ agarose gel stained with SYBR Safe DNA stain. Genome-wide sequence data was generated for C. coli $\mathrm{K} 3$ and K7 (Table 1) using the Illumina HiSeq 2500 platform. Sequencing reads were assembled de novo using Velvet [19] using hash lengths between 39 and 57 and coverage cut-offs between 2 and 10. Assemblies were submitted to the RAST online server [23] for annotation.

\section{Carbon utilisation phenotypic microarray assay}

C. jejuni and C. coli isolates were cultured from $\left(-80^{\circ} \mathrm{C}\right)$ frozen stocks on Columbia Blood Agar (CBA) containing $5 \%$ horse blood (HB) for $48 \mathrm{~h}$ at $37^{\circ} \mathrm{C}$. Cultures were transferred onto Mueller Hinton agar and incubated as before for an additional $48 \mathrm{~h}$. The bacteria were then harvested from agar plates and resuspended into IF-0a inoculating fluid (Biolog, Hayward, CA, USA) and adjusted to $16 \%$ transmittance (or using an optical density (OD) measuring device (Turbidimeter, Biolog) a $\mathrm{OD}_{600}=0.8$ ). The cell suspension was mixed with an additive solution containing tetrazolium violet (Redox dye D) as a redox indicator dye, PM1 or PM2A additive and water, as per the manufacturer's instructions. A final volume of $100 \mu \mathrm{l}$ was added to each of the 96 wells in the carbon utilisation plates, PM1 and PM2A, or bespoke propionic acid only PM plates (Biolog). Care was taken to carefully maintain microaerobic conditions at all times, and inoculated PM plates were placed into gas impermeable bags with a Campy Gen Compact Sachet (Oxoid, UK) during the assay. The inoculated PM1 and PM2A plates were immediately placed in an Omnilog automatic plate reader (Biolog) for incubation at $37^{\circ} \mathrm{C}$. Metabolism of the various carbon sources was recorded every 15 min over a $90 \mathrm{~h}$ period as reduction of the tetrazolium violet dye, producing a purple colour, indicative of active bacterial respiration. The bespoke propionic plates were immediately placed in a variable atmosphere incubator (VAIN) (Don Whitley Scientific, UK) under microaerobic conditions $\left(5 \% \mathrm{O}_{2}, 85 \% \mathrm{~N}_{2}, 10 \% \mathrm{CO}_{2}\right)$ at $37^{\circ} \mathrm{C}$ for up to 5 days. Metabolism of propionic acid was recorded daily over five days as a reduction of the tetrazolium violet dye, producing a purple colour, indicative of active bacterial respiration. Abiotic negative control plates containing all components except for cells were also analysed. Initially, we performed the abiotic control experiments to identify carbon sources that could indicate in false positive results due to auto- reduction of the dye. False positive results observed in PM1 were L-arabinose, D-xylose, D-ribose, L-lyxose. Potential false positive results observed in PM2 were, D-arabinose, 2-deoxy D ribose, D glucosamine, 5-keto D gluconic acid, and dihyroxyacetone. Results for these carbon sources were subsequently excluded from further analysis.

\section{Bioinformatics analysis}

The Kyoto Encyclopaedia of Gene and Genomes (KEGG (http://www.genome.jp/kegg) was employed to determine propanoate metabolism pathways to which the proteins were assigned. The RAST webserver [23] was used to automatically annotate the genome sequences and to carry out KEGG pathway comparisons. To search for conserved regions in the sequences of propionate-CoA ligase and 2-methyl citrate synthase, gene sequences from newly sequenced C. coli isolates K3 and K7 were aligned with homologues in C. coli genome sequences available through the National Center for Biotechnology Information (NCBI) website available at (http://www.ncbi.nlm.nih.gov/). Homology searches were performed using the Blastn tools [25] and multiple sequence alignments were carried out using the computer software Clone Manager 9 (Cary, North Carolina USA).

\section{Genetic screening for propionate-CoA ligase and 2 methyl citrate synthase}

A 522 bp portion of the propionate-CoA ligase was amplified using the PCR from 43 strains of $C$. jejuni DNA and 14 C. coli DNA using the primers PA2 (5'- ATA GGG TGC TTG ATG ATA GCG ATG GG-3' and 5'- GAA GCA TAT TTG CTC TAT ATT GTG GGC GTT-3'). A 843 bp portion of the 2 methyl citrate synthase was amplified using the PCR from 43 strains of $C$. jejuni DNA and 14. C. coli DNA using the primers PA1 ( $5^{\prime}$ - TAA AAA AAC GGG TGG ATT GGC AGG AGT TAT-3' and 5'GTG CAT TTC TAG GAT CAC CTC CAA GTC-3'. A $250 \mathrm{bp}$ portion of the internal control gene $\mathrm{glt} A$ was also amplified to check the fidelity of the PCR for all Campylobacter strains using the primers gltA ( $5^{\prime}$ - TAA AAT CCC TAC TAT AGT GGC CAC CG-3' and 5'GCA TAA GGA TGA GCA TGA GTT GAA CC-3'). Amplifications were carried out in a $50 \mu \mathrm{l}$ reaction mix containing 2-5 $\mu \mathrm{l}$ DNA and using Red Hot Start Polymerase (Qiagen Ltd) and then subjected to PCR using the following cycles; for PA1/ PA2 $96^{\circ} \mathrm{C}$ for 15 minutes, followed by 25 cycles of 1 minute at $94^{\circ} \mathrm{C}, 1.5 \mathrm{~min}$ at $59.4^{\circ} \mathrm{C}, 1.5 \mathrm{~min}$ at $72^{\circ} \mathrm{C}$, and $7 \mathrm{~min}$ at $72^{\circ} \mathrm{C}$; for $\mathrm{gltA} 15 \mathrm{~min}$ at $96^{\circ} \mathrm{C}, 30$ cycles of 1 minute at $94^{\circ} \mathrm{C}$, 1 minute at $59.4^{\circ} \mathrm{C}, 1.5 \mathrm{~min}$ at $72^{\circ} \mathrm{C}$ and $7 \mathrm{~min}$ at $72^{\circ} \mathrm{C}$. 


\section{Additional files}

\section{Additional file 1: Raw data on carbon utilisation of $C$. jejuni and $C$.} coli strains using Biolog analysis.

Additional file 2: Comparison of (a) 2-methyl citrate synthase and (b) propionate-CoA ligase amino acid sequences from C. coli strain The amino acid sequences were analysed by computer software Clone Manager Professional Suite version 9 (Cary, North Carolina USA). Dashed lines represent gaps generated by the analysis software. The identical amino acids are shaded in pale green and the strains can be identified by strain name. The amino acid sequence of 2-methyl citrate synthase and propionate-CoA ligase proteins can be accessed through the NCBI protein database under NCBI accession numbers AAFL01000003.1 (RM2228) [18], AEER01000027.1 (JV 20), AIMK01000002.1 (Z163), AIMJ01000007.1 (90-3), AIML01000019.1 (2548).

\section{Competing interests}

The authors declare that they have no competing interests.

\section{Authors' contributions}

OLC and SW conceived and designed the experiments. SW, JN, EY performed the experiments. CMS and DJS carried out genome assembly and comparative genomics. SW, JN, DJS, RMLR, RWT and OLC analysed the data. SW and OLC wrote the first draft of the paper and SW, JN, EL, DJS, RMLR, RWT OLC contributed to subsequent versions. All authors read and approved the final manuscript

\section{Acknowledgements}

This work was generously supported by a Wellcome Trust Institutional Strategic Support Award (WT097835MF). This work was partly funded by UK Biotechnology and Biological Science Research Council (BBSRC) grant BB/ 1024631/1 (O.L.C., R.W.T and D.J.S.). We acknowledge Dr Konrad Paszkiewicz and Dr Karen Moore for assistance with whole genome sequencing and to James Harrison for submitting the sequence data to GenBank. We thank Dr. Sunee Korbrisate for providing C. jejuni strains Cj1, Cj2, Cj3, Cj5 from Mahidol University Hospital in Thailand

\section{Author details}

'Biosciences, College of Life and Environmental Sciences, University of Exeter, Geoffrey Pope Building, Stocker Road, Exeter EX4 4QD, UK. ${ }^{2}$ Faculty of Health and Medical Sciences, School of Veterinary Medicine, University of Surrey, Guildford, Surrey GU2 7XH, UK. ${ }^{3}$ Department of Bacteriology, Animal Health and Veterinary Laboratories Agency, Weybridge, Surrey KT15 3NB, UK. ${ }^{4}$ Faculty of Health and Medical Sciences, School of Biosciences and Medicine, University of Surrey, Guildford, Surrey GU2 7XH, UK.

Received: 12 May 2014 Accepted: 2 October 2014

Published online: 28 October 2014

\section{References}

1. Oporto B, Esteban Jl, Aduriz G, Juste RA, Hurtado A: Prevalence and strain diversity of thermophilic campylobacters in cattle, sheep and swine farms. J Appl Microbiol 2007, 103:977-984.

2. Boes J, Nersting L, Nielsen EM, Kranker S, Enoe C, Wachmann HC, Baggesen $\mathrm{DL}$ : Prevalence and diversity of campylobacter jejuni in pig herds on farms with and without cattle or poultry. J Food Prot 2005, 68:722-727.

3. Hepworth PJ, Ashelford KE, Hinds J, Gould KA, Witney AA, Williams NJ, Leatherbarrow H, French NP, Birtles RJ, Mendonca C, Dorrell N, Wren BW, Wigley P, Hall N, Winstanley C: Genomic variations define divergence of water/wildlife-associated campylobacter jejuni niche specialists from common clonal complexes. Environ Microbiol 2011, 13:1549-1560.

4. Stahl M, Friis LM, Nothaft H, Liu X, Li J, Szymanski CM, Stintzi A: L-fucose utilization provides campylobacter jejuni with a competitive advantage. Proc Natl Acad Sci U S A 2011, 108:7194-7199.

5. Hofreuter D, Novik V, Galan JE: Metabolic diversity in campylobacter jejuni enhances specific tissue colonization. Cell Host Microbe 2008, 4:425-433.

6. Leon-Kempis MD, Guccione E, Mulholland F, Williamson MP, Kelly DJ: The campylobacter jejuni PEB1a adhesin is an aspartate/glutamate-binding protein of an $A B C$ transporter essential for microaerobic growth on dicarboxylic amino acids. Mol Microbiol 2006, 60:1262-1275.
7. Velayudhan J, Jones MA, Barrow PA, Kelly DJ: L-serine catabolism via an oxygen-labile L-serine dehydratase is essential for colonization of the avian gut by campylobacter jejuni. Infect Immun 2004, 72:260-268.

8. Bergey DH, Holt JGE, Krieg NR, Sneath PHA, Mair NS, Sharpe ME, Williams ST: Bergey's manual of systematic bacteriology. Baltimore, USA: Williams and Wilkins; 1984.

9. Thomas MT, Shepherd M, Poole RK, van Vliet AH, Kelly DJ, Pearson BM: Two respiratory enzyme systems in campylobacter jejuni NCTC 11168 contribute to growth on L-lactate. Environ Microbiol 2011, 13:48-61.

10. Velayudhan J, Kelly DJ: Analysis of gluconeogenic and anaplerotic enzymes in campylobacter jejuni: an essential role for phosphoenolpyruvate carboxykinase. Microbiol-Sgm 2002, 148:685-694

11. Hofreuter D, Mohr J, Wensel O, Rademacher S, Schreiber K, Schomburg D, Gao B, Galan JE: Contribution of amino acid catabolism to the tissue specific persistence of campylobacter jejuni in a murine colonization model. PLoS One 2012, 7:e50699.

12. Parsons $C M$, Potter $L M$, Brown RD Jr: Effects of dietary carbohydrate and of intestinal microflora on excretion of endogenous amino acids by poultry. Poult Sci 1983, 62:483-489.

13. Wright JA, Grant AJ, Hurd D, Harrison M, Guccione EJ, Kelly DJ, Maskell DJ: Metabolite and transcriptome analysis of campylobacter jejuni in vitro growth reveals a stationary-phase physiological switch. Microbiology 2009, 155:80-94.

14. Parkhill J, Wren BW, Mungall K, Ketley JM, Churcher C, Basham D, Chillingworth T, Davies RM, Feltwell T, Holroyd S, Jagels K, Karyshev AV, Moule S, Pallen MJ, Penn CW, Quail MA, Rajandream MA, Rutherford KM, van Vliet AH, Whitehead S, Barrell BG: The genome sequence of the food-borne pathogen campylobacter jejuni reveals hypervariable sequences. Nature 2000, 403:665-668.

15. Muraoka WT, Zhang Q: Phenotypic and genotypic evidence for L-fucose utilization by campylobacter jejuni. J Bacterio/ 2011, 193:1065-1075.

16. Guccione E, Leon-Kempis Mdel R, Pearson BM, Hitchin E, Mulholland F van Diemen PM, Stevens MP, Kelly DJ: Amino acid-dependent growth of campylobacter jejuni: key roles for aspartase (AspA) under microaerobic and oxygen-limited conditions and identification of AspB (Cj0762), essential for growth on glutamate. Mol Microbiol 2008, 69:77-93.

17. Macfarlane GT, Macfarlane S: Bacteria, colonic fermentation, and gastrointestinal health. J AOAC Int 2012, 95:50-60.

18. Fouts DE, Mongodin EF, Mandrell RE, Miller WG, Rasko DA, Ravel J, Brinkac LM, DeBoy RT, Parker CT, Daugherty SC Dodson RJ, Durkin AS, Madupu R, Sullivan SA, Shetty JU, Ayodeji MA, Shvartsbeyn A, Schatz MC, Badger JH, Fraser CM, Nelson KE: Major structural differences and novel potential virulence mechanisms from the genomes of multiple Campylobacter species. PLOS Biol 2005, 3(1):e15.

19. Pearson BM, Gaskin DJ, Segers RP, Wells JM, Nuijten PJ, van Vliet AH: The complete genome sequence of Campylobacter jejuni strain 81116 (NCTC11828). J Bacterio/ 2007, 189((22):8402-8403.

20. Korlath JA, Osterholm MT, Judy LA, Forfang JC, Robinson RA: A pointsource outbreak of campylobacteriosis associated with consumption of raw milk. J Infect Dis 1985, 152(3):592-596.

21. Penner JL, Hennessy JN, Congi RV: Serotyping of Campylobacter jejuni and Campylobacter coli on the basis of thermostable antigens. Eur J Clin Microbiol 1983, 2(4):378-383.

22. Skirrow MB: Campylobacter enteritis: a "new" disease. Br Med J 1977, 2(6078):9-11.

23. Aziz RK, Bartels D, Best AA, DeJongh M, Disz T, Edwards RA, Formsma K, Gerdes S, Glass EM, Kubal M, Meyer F, Olsen GJ, Olson R, Osterman AL, Overbeek RA, McNeil LK, Paarmann D, Paczian T, Parrello B, Pusch GD, Reich C, Stevens R, Vassieva O, Vonstein V, Wilke A, Zagnitko O: The RAST server: rapid annotations using subsystems technology. BMC Genomics 2008, 9:75.

24. Wheeler DL, Barrett T, Benson DA, Bryant SH, Canese K, Chetvernin V, Church DM, DiCuccio M, Edgar R, Federhen S, Geer LY, Helmberg W, Kapustin Y, Kenton DL, Khovayko O, Lipman DJ, Madden TL, Maglott DR, Ostell J, Pruitt KD, Schuler GD, Schriml LM, Sequeira E, Sherry ST, Sirotkin K, Souvorov A, Starchenko G, Suzek TO, Tatusov R, Tatusova TA, et al: Database resources of the national center for biotechnology information. Nucleic Acids Res 2006, 34:D173-D180.

25. Altschul SF, Madden TL, Schaffer AA, Zhang J, Zhang Z, Miller W, Lipman DJ: Gapped BLAST and PSI-BLAST: a new generation of protein database search programs. Nucleic Acids Res 1997, 25:3389-3402. 
26. Pruitt KD, Tatusova T, Maglott DR: NCBI reference sequences (RefSeq): a curated non-redundant sequence database of genomes, transcripts and proteins. Nucleic Acids Res 2007, 35:D61-D65.

27. Kelly AF, Park SF, Bovill R, Mackey BM: Survival of campylobacter jejuni during stationary phase: evidence for the absence of a phenotypic stationary-phase response. App/ Environ Microbiol 2001, 67:2248-2254.

28. Booth IR, Higgins CF: Enteric bacteria and osmotic stress: intracellular potassium glutamate as a secondary signal of osmotic stress? FEMS Microbiol Rev 1990, 6:239-246.

29. Wood JM: Proline porters effect the utilization of proline as nutrient or osmoprotectant for bacteria. J Membr Biol 1988, 106:183-202.

30. Empadinhas N, Albuquerque L, Mendes V, Macedo-Ribeiro S, da Costa MS: Identification of the mycobacterial glucosyl-3-phosphoglycerate synthase. FEMS Microbiol Lett 2008, 280:195-202.

31. Coulter SN, Schwan WR, Ng EY, Langhorne MH, Ritchie HD, Westbrock Wadman S, Hufnagle WO, Folger KR, Bayer AS, Stover CK: Staphylococcus aureus genetic loci impacting growth and survival in multiple infection environments. Mol Microbiol 1998, 30:393-404.

32. Peng K, Monack DM: Indoleamine 2,3-dioxygenase 1 is a lung-specific innate immune defense mechanism that inhibits growth of francisella tularensis tryptophan auxotrophs. Infect Immun 2010, 78:2723-2733.

33. Thomas DK, Lone AG, Selinger LB, Taboada EN, Uwiera RR, Abbott DW Inglis GD: Comparative variation within the genome of campylobacter jejuni NCTC 11168 in human and murine hosts. PLoS One 2014, 9:e88229.

34. Revez J, Schott T, Llarena AK, Rossi M, Hanninen ML: Genetic heterogeneity of campylobacter jejuni NCTC 11168 upon human infection. Infect Genet Evol 2013, 16:305-309.

35. Line JE, Hiett KL, Guard-Bouldin J, Seal BS: Differential carbon source utilization by campylobacter jejuni 11168 in response to growth temperature variation. J Microbiol Methods 2010, 80:198-202

36. Chi FH, Lin PH, Leu MH: Quick determination of malodor-causing fatty acids in manure by capillary electrophoresis. Chemosphere 2005, 60:1262-1269.

37. Eberhard M, Hennig U, Kuhla S, Brunner RM, Kleessen B, Metges CC: Effect of inulin supplementation on selected gastric, duodenal, and caecal microbiota and short chain fatty acid pattern in growing piglets. Arch Anim Nutr 2007, 61:235-246.

38. Coker AO, Isokpehi RD, Thomas BN, Amisu KO, Obi CL: Human campylobacteriosis in developing countries. Emerg Infect Dis 2002, 8:237-244.

39. Totten PA, Patton CM, Tenover FC, Barrett TJ, Stamm WE, Steigerwalt AG, Lin JY, Holmes KK, Brenner DJ: Prevalence and characterization of hippurate-negative campylobacter jejuni in king county, Washington. J Clin Microbiol 1987, 25:1747-1752.

40. Steinhauserova I, Ceskova J, Fojtikova K, Obrovska I: Identification of thermophilic campylobacter spp. By phenotypic and molecular methods. J Appl Microbiol 2001, 90:470-475.

41. Mandrell RE, Harden LA, Bates A, Miller WG, Haddon WF, Fagerquist CK: Speciation of campylobacter coli, C. Jejuni, C. Helveticus, C. Lari, C. Sputorum, and C. Upsaliensis by matrix-assisted laser desorption ionization-time of flight mass spectrometry. Appl Environ Microbiol 2005, 71:6292-6307.

42. Eyers M, Chapelle S, Van Camp G, Goossens H, De Wachter R: Discrimination among thermophilic campylobacter species by polymerase chain reaction amplification of $23 \mathrm{~S}$ rRNA gene fragments. J Clin Microbiol 1993, 31:3340-3343.

43. Gonzalez I, Grant KA, Richardson PT, Park SF, Collins MD: Specific identification of the enteropathogens campylobacter jejuni and campylobacter coli by using a PCR test based on the ceuE gene encoding a putative virulence determinant. J Clin Microbiol 1997, 35:759-763.

44. Klena JD, Parker CT, Knibb K, Ibbitt JC, Devane PM, Horn ST, Miller WG, Konkel ME: Differentiation of campylobacter coli, campylobacter jejuni, campylobacter lari, and campylobacter upsaliensis by a multiplex PCR developed from the nucleotide sequence of the lipid a gene IpxA. J Clin Microbiol 2004, 42:5549-5557.

\section{doi:10.1186/s12866-014-0262-y}

Cite this article as: Wagley et al:: Differences in carbon source utilisation distinguish Campylobacter jejuni from Campylobacter coli. BMC Microbiology 2014 14:262.

\section{Submit your next manuscript to BioMed Central and take full advantage of:}

- Convenient online submission

- Thorough peer review

- No space constraints or color figure charges

- Immediate publication on acceptance

- Inclusion in PubMed, CAS, Scopus and Google Scholar

- Research which is freely available for redistribution 